\title{
Association of Serum Ceruloplasmin Level with Obesity: Some Components of Metabolic Syndrome and High-Sensitive C-Reactive Protein in Iran
}

\author{
Seyyed Morteza Safavi, ${ }^{1}$ Rahele Ziaei, ${ }^{1}$ and Mohammad Reza Maracy ${ }^{2}$ \\ ${ }^{1}$ School of Nutrition and Food Sciences, Isfahan University of Medical Sciences, Isfahan 81745, Iran \\ ${ }^{2}$ School of Health, Isfahan University of Medical Sciences, Isfahan 81745, Iran \\ Correspondence should be addressed to Rahele Ziaei, ziaei_r4@yahoo.co.in
}

Received 17 October 2012; Accepted 18 December 2012

Academic Editor: Roya Kelishadi

Copyright (C) 2012 Seyyed Morteza Safavi et al. This is an open access article distributed under the Creative Commons Attribution License, which permits unrestricted use, distribution, and reproduction in any medium, provided the original work is properly cited.

\begin{abstract}
Background. One of the mechanisms that has been suggested for obesity related metabolic disturbances is obesity-induced inflammation. Pro-inflammatory cytokines generated in adipose tissue can increase hepatic synthesis of inflammation-sensitive plasma proteins (ISPs) including ceruloplasmin (Cp). In this study we aimed to investigate the relation between serum Cp level and obesity. Methods. 61 persons with body mass index (BMI) $\geq 25 \mathrm{~kg} / \mathrm{m}^{2}$ (case group) and 61 persons with BMI $<25 \mathrm{~kg} / \mathrm{m}^{2}$ (control group) were included in this study with a case-control design. Serum Cp levels, triglyceride level, fating blood glucose, total cholesterol, LDL-cholesterol, HDL-cholesterol and hsCRP were measured in both groups. Results. We did not observe any significant association between serum $\mathrm{Cp}$ level and BMI in all subjects [OR: 1.02 (CI, 0.967 to 1.07)] and in case $(\beta=0.012$, $P=0.86)$ and control groups $(\beta=0.49, P=0.07)$ separately. However, in control group, this positive association was marginally significant. We found a positive correlation between serum $\mathrm{Cp}$ level and serum triglyceride level. Conclusion. Serum Cp level was not related to obesity in this group of subjects. None of the baseline variables could predict obesity in this group of subjects, including serum Cp level, FBS, total cholesterol, LDL and HDL- cholesterols and hsCRP.
\end{abstract}

\section{Introduction}

Obesity is a continuously worldwide public health problem that is closely associated with chronic diseases like dyslipidemia, metabolic syndrome, type 2 diabetes, atherosclerosis, and cardiovascular diseases $[1,2]$. Different studies were done in order to recognize the involved mechanisms in pathophysiology of obesity and obesity-related diseases $[3,4]$. Among these mechanisms, obesity-induced inflammation proposed as the potential link of obesity-related metabolic disturbances and chronic diseases [5].

Some studies have reported the positive correlation between body fat mass and inflammation-sensitive plasma proteins or ISPs, along with other inflammatory markers $[4,6,7]$. Kim et al., in a cross-sectional study with proteomic approach, reported that ceruloplasmin and fibrinogen were overexpressed in obese subjects [8]. In addition, in a cohort study on healthy men, aiming to study ISPs effects on modifying cardiovascular risk in obese subjects, there was not any association between ceruloplasmin level and BMI [9]. Proinflammatory cytokines produced in adipose tissue can increase hepatic synthesis of ISPs, which are known as important cardiovascular disease risk factors $[7,8]$.

Ceruloplasmin $(\mathrm{Cp})$ is a member of ISPs family that is used in clinical practice to measure the degree of inflammation. Accumulating epidemiological data have reported that serum ceruloplasmin level increases in subjects with cardiovascular disorders, like atherosclerosis, abdominal aortic aneurysm, unstable angina, vasculitis, peripheral vascular diseases, and also in type 2 diabetes [10-19]. Most attention in recent years has been devoted to the concept that obesity elicits a chronic, low-grade systemic 
inflammatory response [20]. Limited studies investigated the association between serum ceruloplasmin level and obesity $[6,8]$, and mainly, these studies focused on the association of this protein and cardiovascular diseases [9, 21-24]. We have no study in our country about this issue. Because serum Cp levels are affected by genetic and environmental factors, we can expect different results in different population studies [21], on the other hand, because obesity pattern in Iran is different from those in other countries, conducting such studies appears to be necessary. This study aims to investigate the association between serum ceruloplasmin level and obesity and some of the metabolic and inflammatory indexes, in order to recognize new biomarkers for obesity.

\section{Methods}

2.1. Study Design. The study was conducted in case-control design. The subjects with BMI above or equal to $25 \mathrm{~kg} / \mathrm{m}^{2}$ were placed in case group and with BMI lower than $25 \mathrm{~kg} / \mathrm{m}^{2}$ in control group. This was based on their body mass index or BMI. Collecting data was from March 2012 to July 2012. The subjects in case group (61 subjects) were selected from overweight and obese subjects, referring to nutrition clinics that had the qualification to enter the study (aged between 25-60 years), in continuous manner and for the control group (61 subjects), we selected one subject with normal weight per each case, that again, was qualified to enter the study. Factors like age and sex were controlled for sampling. Subjects with diseases like coronary artery disease, stroke, peripheral vascular diseases, type 2 diabetes, liver or kidney dysfunction, history of regular use of any medication that could affect cardiovascular function, and pregnant women excluded from the study. To determine sample size, we used the following expression:

$$
n=\frac{z_{1-\alpha / 2}^{2}\left[p_{1}\left(1-p_{1}\right)+p_{2}\left(1-p_{2}\right)\right]}{d^{2}},
$$

where $z_{1-\alpha / 2}$ is the study confidence coefficient $95 \%$ and equal to $1 / 96,\left(p_{1}\right)$ obesity ratio $30 \%,\left(p_{2}\right)$ normal ratio $50 \%$, and $(d)$ sampling error and equal to $0 / 17$.

2.2. Anthropometric and Biochemical Parameters. Body Weight and height were measured by a digital scale and with the minimum clothing and without shoes. BMI obtained by dividing weight $(\mathrm{kg})$ by height square $\left(\mathrm{m}^{2}\right)$. Waist circumference was measured by a flexible meter at the level of minimum circumference. venous blood specimens after 14 hours of fasting were collected by an experienced specialist for measuring serum ceruloplasmin level, fasting blood sugar (FBS), lipid profile including triglyceride, total cholesterol, LDL cholesterol (light-density lipoprotein), HDL cholesterol (high-density lipoprotein) and high-sensitive C-reactive protein level (hSCRP). Serum ceruloplasmin level was measured with colorimetric method, hsCRP with immunoturbidimetric method and FBS, total cholesterol, LDL, and HDL cholesterol were measured with enzymatic method. Before entering the study, the purpose of this study was explained for all the participants and the written consent was obtained. Baseline characteristics of the participants, including demographic characteristics, anthropometric parameters, and medical history, were collected by measurement and completing a questionnaire.

2.3. Statistical Methods. The SPSS software version 18 (version 18, SPSS Inc, Chicago) was used for statistical analysis. Each variable was examined for normal distribution. Pearson correlation coefficient was used to evaluate correlation between variables, and we used linear multiple regression to determine the relation between ceruloplasmin level with BMI and other variables. The effect of variables like age, sex, smoking, hypertension, total cholesterol, LDL and HDL cholesterol, triglyceride, and hsCRP was adjusted as confounder variables. $P$ value less than $0 / 05$ was considered statistically significant.

\section{Results}

Baseline characteristics of the participants are shown in Table 1. In this study, 122 subjects ( 55 male and 67 female) were investigated, 61 subjects were in case group and 61 subjects in control group. There was a significant difference in LDL cholesterol level between two groups, as we see in Table $1.5 \%$ of subjects was found with hypertension (subjects with blood pressure $\geq 140 / 90 \mathrm{mmHg}$ ) and 15/6\% with hyperlipidemia (subjects with serum triglyceride level $\geq 200 \mathrm{mg} / \mathrm{dL}$, or total cholesterol level $\geq 200 \mathrm{mg} / \mathrm{dL}$, or LDL cholesterol level $\geq 130 \mathrm{mg} / \mathrm{dL}$ were considered hyperlipidemic). There was no significant difference between sex, hypertension, hyperlipidemia, hyperthyroidism ratios, and also drug consumption between the two groups.

The mean serum Cp level in control group was 29/7 \pm $7 / 1 \mathrm{mg} / \mathrm{dL}$ and in case group was $30 / 8 \pm 7 / 6 \mathrm{mg} / \mathrm{dL}$. The difference of mean serum Cp level between two groups was not significant $(P=0 / 4)$. There was not any significant association between serum Cp level and BMI in all subjects (Table 2), and when we investigated this association in case and control groups separately, this association was not significant again; however, in control group, this positive association was close to significance level (Table 3). Correlation analysis showed that there was a positive significant correlation between serum $\mathrm{Cp}$ level and serum triglycerides $(P<0 / 05, r=0 / 21)$. But the correlation was not significant for serum $\mathrm{Cp}$ level and other variables like FBS, total cholesterol, LDL and HDL cholesterols, hsCRP, age, and sex. In multivariate analysis model, there was no significant association of serum ceruloplasmin level with waist circumference and $\operatorname{BMI}[F(2,48)=2 / 2, P=0 / 122]$. Also, there was not any significant association between serum ceruloplasmin level with body weight and height $[F(2,111)=0 / 33, P=0 / 71]$.

In linear multiple regression, none of the baseline variables could predict obesity in this group of subjects, including serum Cp level, FBS, total cholesterol, LDL and HDL cholesterols, and hsCRP. 
TABLE 1: Baseline and serum characteristics of study subjects. Data are presented as means \pm SD.

\begin{tabular}{lccc}
\hline & $\begin{array}{c}\text { Control group } \\
(n=61)\end{array}$ & $\begin{array}{c}\text { Case group } \\
(n=61)\end{array}$ & $P$ value \\
\hline Age (years) & $41 / 1 \pm 9 / 6$ & $41 / 8 \pm 10 / 2$ & $0 / 7$ \\
Males/females & $32: 29$ & $34: 27$ & $0 / 88$ \\
HTN (\%) & $5 / 1$ & $4 / 8$ & $0 / 93$ \\
Hyperlipidemia (\%) & $13 / 6$ & $17 / 5$ & $0 / 55$ \\
Hypothyroidism (\%) & $3 / 4$ & $7 / 9$ & $0 / 28$ \\
BMI $\left(\mathrm{kg} / \mathrm{m}^{2}\right)$ & $23 / 5 \pm 1 / 3$ & $30 / 3 \pm 4 / 3$ & $<0 / 001$ \\
WC $(\mathrm{cm})$ & $87 / 3 \pm 6 / 9$ & $96 / 6 \pm 11 / 8$ & $<0 / 001$ \\
FBS $(\mathrm{mg} / \mathrm{dL})$ & $95 / 7 \pm 8 / 9$ & $97 / 4 \pm 9 / 1$ & $0 / 3$ \\
Total cholesterol (mg/dL) & $150 / 6 \pm 28 / 7$ & $155 / 5 \pm 29 / 3$ & $0 / 35$ \\
Triglyceride $(\mathrm{mg} / \mathrm{dL})$ & $126 / 6 \pm 61$ & $142 / 2 \pm 62 / 5$ & $0 / 16$ \\
LDL cholesterol $(\mathrm{mg} / \mathrm{dL})$ & $82 / 4 \pm 18 / 9$ & $90 / 5 \pm 22 / 8$ & $<0 / 05$ \\
HDL cholesterol (mg/L) & $47 / 9 \pm 11 / 1$ & $47 / 7 \pm 9 / 3$ & $0 / 9$ \\
hs-CRP $(\mathrm{mg} / \mathrm{L})$ & $1 / 88 \pm 0 / 96$ & $2 / 14 \pm 1 / 15$ & $0 / 17$ \\
Ceruloplasmin $(\mathrm{mg} / \mathrm{dL})$ & $29 / 7 \pm 7 / 1$ & $30 / 8 \pm 7 / 6$ & $0 / 4$ \\
\hline
\end{tabular}

WC indicates waist circumference.

HTN indicates hypertension.

TABLE 2: BMI in relation to serum ceruloplasmin level. Results for logistic regression analysis.

\begin{tabular}{lccc}
\hline & \multicolumn{3}{c}{ BMI } \\
& OR ${ }^{*}$ & $P$ value & $95 \%$ CI \\
\hline Ceruloplasmin & $1 / 021$ & $0 / 46$ & $(0 / 967-1 / 077)$ \\
\hline${ }^{*}$ Odds ratio adjusted for age, gender, smoking, hypertension, FBS, total \\
cholesterol, LDL-cholesterol, HDL-cholesterol, triglyceride and hs-CRP.
\end{tabular}

\section{Discussion}

In this case-control study, there was no significant association between serum Cp level and obesity in all subjects and in case and control groups separately. However, in control group, this positive relation was close to significance. Also, we found a significant positive correlation between serum $\mathrm{Cp}$ level and serum triglyceride level. So far, the association between serum $\mathrm{Cp}$ level and obesity has not been investigated in Iran. $\mathrm{Cp}$ is a copper-containing $\alpha-2$ glycoprotein which contains seven copper atoms per molecule and accounts for $95 \%$ of the total circulating copper in healthy adults. It is involved in coagulation, angiogenesis, defence against oxidant stress and iron homeostasis [8].

A limited number of studies have investigated the association between serum $\mathrm{Cp}$ and obesity, and most of them have reported a positive correlation between body fat mass and inflammation-sensitive plasma proteins or ISPs, like Cp, along with other inflammatory markers $[6,8]$. Proinflammatory cytokines generated in adipose tissue can increase hepatic synthesis of ISPs. These proteins are recognized as cardiovascular disease risk factors and some of them like haptoglobin, fibrinogen, $\alpha_{1}$-antitrypsin, and Cp were used in clinical practice to measure the degree of inflammation [8]. In this study, there was no significant association between serum Cp level and obesity in all subjects, and Engström et al. study [9] in (2004) supports this finding. In that study, in addition to $\mathrm{Cp}$, they investigated some of the other ISPs, among which $\mathrm{Cp}$ and $\alpha_{1}$-antitrypsin, had not any association with BMI. Serum Cp level can be affected by genetic and environmental factors like diet, life style, and diseases [21]. Thus, we may find different results in the study of different populations. The mechanisms by which $\mathrm{Cp}$ is related to obesity has not been identified; however, it is possible that $\mathrm{Cp}$ is involved in the inflammatory pathway linked to obesity [8]. In addition, obesity is associated with oxidative stress. Therefore, elevated serum Cp levels may signal abnormally high oxidant stress [9]. Göçmen et al. [21] showed that $\mathrm{Cp}$ can act, depending on its concentration, as antioxidant or prooxidant in laboratory conditions. In this study, we tried to investigate the association between serum Cp level and some of the metabolic syndrome elements and also hsCRP, in addition to obesity. Among these indexes, Cp had a significant positive correlation with serum triglyceride level.

One of the limitations of the study is not to measure other ISPs along with $\mathrm{Cp}$, as we explained earlier, the association between obesity and ISPs can differ by their types. Another limitation is the small sample size of this study, due to which, perhaps the association is not significant between $\mathrm{Cp}$ and obesity in all subjects. Not measuring the dietary intakes in study subjects is considered the other limitation, because, in one hand, the intake of some micronutrients, like copper, can affect serum ceruloplasmin level, and on the other hand, it has been found that the degree of macronutrient intake affects the severity of inflammation [9]. Because the use of oral contraceptive pills or OCPs can affect serum ceruloplasmin level the other limitation is not to consider their consumption in the study.

We propose for future studies to consider other ISPs in addition to $\mathrm{Cp}$, to conduct intervening studies in this basis, 
TABLE 3: BMI in relation to serum ceruloplasmin level and other variables, in case and control group separately. Results for linear multiple regression analysis.

\begin{tabular}{|c|c|c|c|c|}
\hline & \multicolumn{2}{|c|}{$\mathrm{BMI}<25$} & \multicolumn{2}{|c|}{$\mathrm{BMI} \geq 25$} \\
\hline & $\beta^{*}(95 \% \mathrm{CI})$ & $P$ value & $\beta(95 \% \mathrm{CI})$ & $P$ value \\
\hline Ceruloplasmin & $0 / 49(-0 / 005-0 / 1)$ & $0 / 072$ & $0 / 012(-0 / 15-0 / 13)$ & $0 / 86$ \\
\hline FBS & $0 / 002(-0 / 03-0 / 04)$ & $0 / 91$ & $0 / 127(-0 / 02-0 / 27)$ & $0 / 1$ \\
\hline Total cholesterol & $0 / 01(-0 / 03-0 / 01)$ & $0 / 33$ & $0 / 005(-0 / 05-0 / 06)$ & $0 / 88$ \\
\hline Triglyceride & $0 / 004(-0 / 004-0 / 01)$ & $0 / 13$ & $0 / 002(-0 / 02-0 / 02)$ & $0 / 88$ \\
\hline LDL cholesterol & $0 / 009(-0 / 01-0 / 03)$ & $0 / 54$ & $0 / 031(-0 / 12-0 / 06)$ & $0 / 51$ \\
\hline hs-CRP & $-0 / 19(-0 / 01-0 / 03)$ & $0 / 225$ & $0 / 54(-1 / 72-0 / 64)$ & $0 / 36$ \\
\hline
\end{tabular}

$* \beta$ indicates regression coefficient that is adjusted for age, gender, smoking, hypertension, FBS, total cholesterol, LDL-cholesterol, HDL-cholesterol, triglyceride and hs-CRP.

and also to conduct this kind of investigations in children. As we discussed earlier, serum Cp level is affected by genetic and environmental factors and we may find different results in the study of different populations. This study is the first one to investigate the association between serum cp level and obesity in Iran.

\section{References}

[1] M. M. Mello, D. M. Studdert, and T. A. Brennan, "Obesitythe new frontier of public health law," The New England Journal of Medicine, vol. 354, no. 24, pp. 2601-2610, 2006.

[2] P. Hossain, B. Kawar, and M. El Nahas, "Obesity and diabetes in the developing world-a growing challenge," The New England Journal of Medicine, vol. 356, no. 3, pp. 213-215, 2007.

[3] T. E. Sonnett, T. L. Levien, B. J. Gates, J. D. Robinson, and R. K. Campbell, "Diabetes mellitus, inflammation, obesity: proposed treatment pathways for current and future therapies," Annals of Pharmacotherapy, vol. 44, no. 4, pp. 701-711, 2010.

[4] L. Bouchard, R. Rabasa-Lhoret, M. Faraj et al., "Differential epigenomic and transcriptomic responses in subcutaneous adipose tissue between low and high responders to caloric restriction," American Journal of Clinical Nutrition, vol. 91, no. 2, pp. 309-320, 2010.

[5] T. Nakayama and Z. Wang, "Inflammation, a link between obesity and cardiovascular disease," Mediators of Inflammation, vol. 2010, Article ID 535918, 17 pages, 2010.

[6] G. Engström, B. Hedblad, L. Stavenow, P. Lind, L. Janzon, and F. Lindgärde, "Inflammation-sensitive plasma proteins are associated with future weight gain," Diabetes, vol. 52, no. 8, pp. 2097-2101, 2003.

[7] G. Engstroem, L. Stavenow, B. Hedblad, P. Lind, K. F. Eriksson, L. Janzon et al., "Inflammation-sensitive plasma proteins, diabetes and mortalityand incidence of myocardial infarction and stroke: a population based study," Arteriosclerosis, Thrombosis, and Vascular Biology, vol. 24, pp. 1498-1502, 2004.

[8] O. Y. Kim, M. J. Shin, J. Moon, and J. H. Chung, "Plasma ceruloplasmin as a biomarker for obesity: a proteomic approach," Clinical Biochemistry, vol. 44, no. 5-6, pp. 351-356, 2011.

[9] G. Engström, B. Hedblad, L. Stavenow et al., "Incidence of obesity-associated cardiovascular disease is related to inflammation-sensitive plasma proteins: a population-based cohort study," Arteriosclerosis, Thrombosis, and Vascular Biology, vol. 24, no. 8, pp. 1498-1502, 2004.

[10] P. L. Fox, C. Mukhopadhyay, and E. Ehrenwald, "Structure, oxidant activity, and cardiovascular mechanisms of human ceruloplasmin,” Life Sciences, vol. 56, no. 21, pp. 1749-1758, 1995.

[11] N. Shukla, J. Maher, J. Masters, G. D. Angelini, and J. Y. Jeremy, "Does oxidative stress change ceruloplasmin from a protective to a vasculopathic factor?" Atherosclerosis, vol. 187, no. 2, pp. 238-250, 2006.

[12] P. L. Fox, B. Mazumder, E. Ehrenwald, and C. K. Mukhopadhyay, "Ceruloplasmin and cardiovascular disease," Free Radical Biology and Medicine, vol. 28, no. 12, pp. 1735-1744, 2000.

[13] M. Pioruńska-Stolzmann, M. Iskra, and W. Majewski, "The activity of cholesterol esterase and ceruloplasmin are inversely related in the serum of men with atherosclerosis obliterans," Medical Science Monitor, vol. 7, no. 5, pp. 940-945, 2001.

[14] R. Memişoğullari and E. Bakan, "Levels of ceruloplasmin, transferrin, and lipid peroxidation in the serum of patients with Type 2 diabetes mellitus," Journal of Diabetes and Its Complications, vol. 18, no. 4, pp. 193-197, 2004.

[15] S. Taysi, F. Polat, M. Gul, R. Sari, and E. Bakan, "Lipid peroxidation, some extracellular antioxidants, and antioxidant enzymes in serum of patients with rheumatoid arthritis," Rheumatology International, vol. 21, no. 5, pp. 200-204, 2002.

[16] M. Daimon, S. Susa, K. Yamatani et al., "Hyperglycemia is a factor for an increase in serum ceruloplasmin in type 2 diabetes," Diabetes Care, vol. 21, no. 9, pp. 1525-1528, 1998.

[17] P. M. Ridker, J. E. Buring, N. R. Cook, and N. Rifai, "Creactive protein, the metabolic syndrome, and risk of incident cardiovascular events: an 8-year follow-up of 14719 initially healthy American women," Circulation, vol. 107, no. 3, pp. 391-397, 2003.

[18] G. Engström, P. Lind, B. Hedblad, L. Stavenow, L. Janzon, and F. Lindgärde, "Effects of cholesterol and inflammationsensitive plasma proteins on incidence of myocardial infarction and stroke in men," Circulation, vol. 105, no. 22, pp. 26322637, 2002.

[19] E. S. Ford, "Body mass index, diabetes, and C-reactive protein among U.S. Adults," Diabetes Care, vol. 22, no. 12, pp. 19711977, 1999.

[20] A. Festa, R. D’Agostino Jr., K. Williams et al., “The relation of body fat mass and distribution to markers of chronic inflammation," International Journal of Obesity, vol. 25, no. 10, pp. 1407-1415, 2001.

[21] A. Y. Göçmen, E. Şahin, E. Semiz, and S. Gümüslü, "Is elevated serum ceruloplasmin level associated with increased risk of coronary artery disease?" Canadian Journal of Cardiology, vol. 24, no. 3, pp. 209-212, 2008.

[22] A. Ziakas, S. Gavrilidis, E. Souliou et al., "Ceruloplasmin is a better predictor of the long-term prognosis compared with 
fibrinogen, CRP, and IL-6 in patients with severe unstable angina," Angiology, vol. 60, no. 1, pp. 50-59, 2009.

[23] E. S. Ford, "Serum copper concentration and coronary heart disease among US adults," American Journal of Epidemiology, vol. 151, no. 12, pp. 1182-1188, 2000.

[24] M. Iskra and W. Majewski, "Activities of copper,zincsuperoxide dismutase in erythrocytes and ceruloplasmin in serum in chronic ischemia of lower limbs," International Journal of Clinical and Laboratory Research, vol. 29, no. 2, pp. 64-67, 1999. 


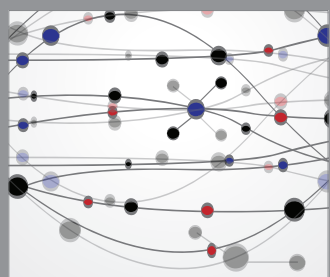

The Scientific World Journal
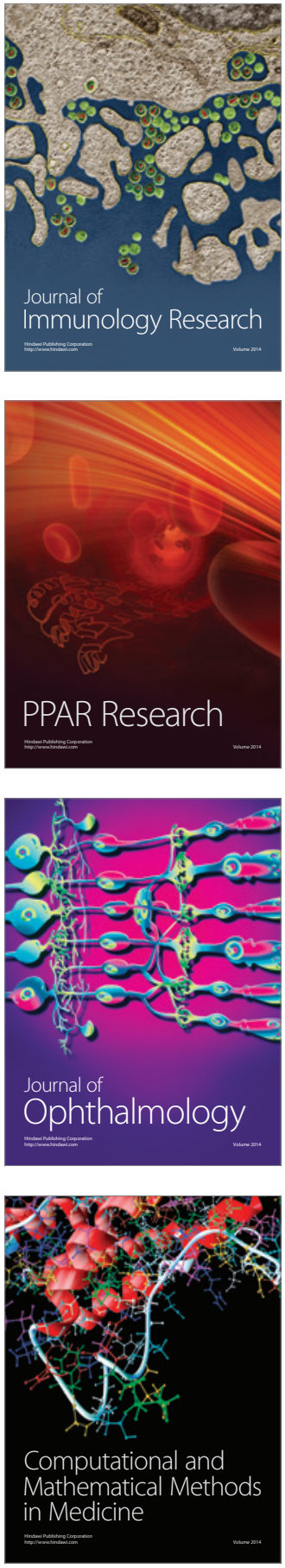

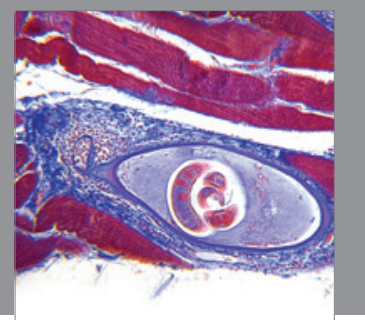

Gastroenterology

Research and Practice
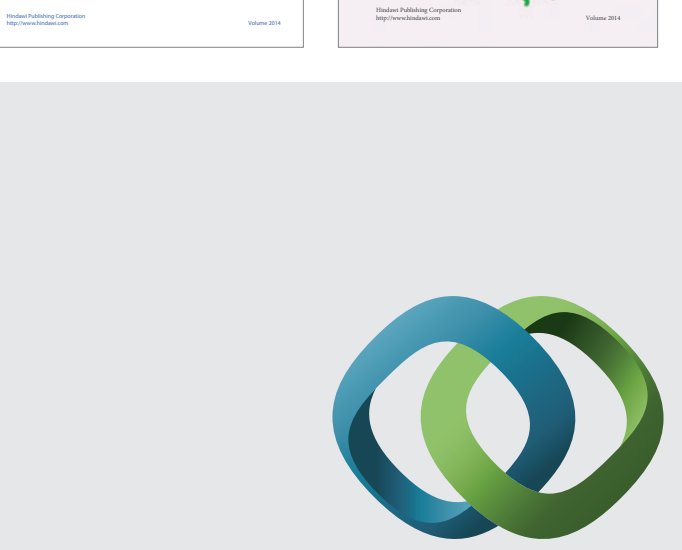

\section{Hindawi}

Submit your manuscripts at

http://www.hindawi.com
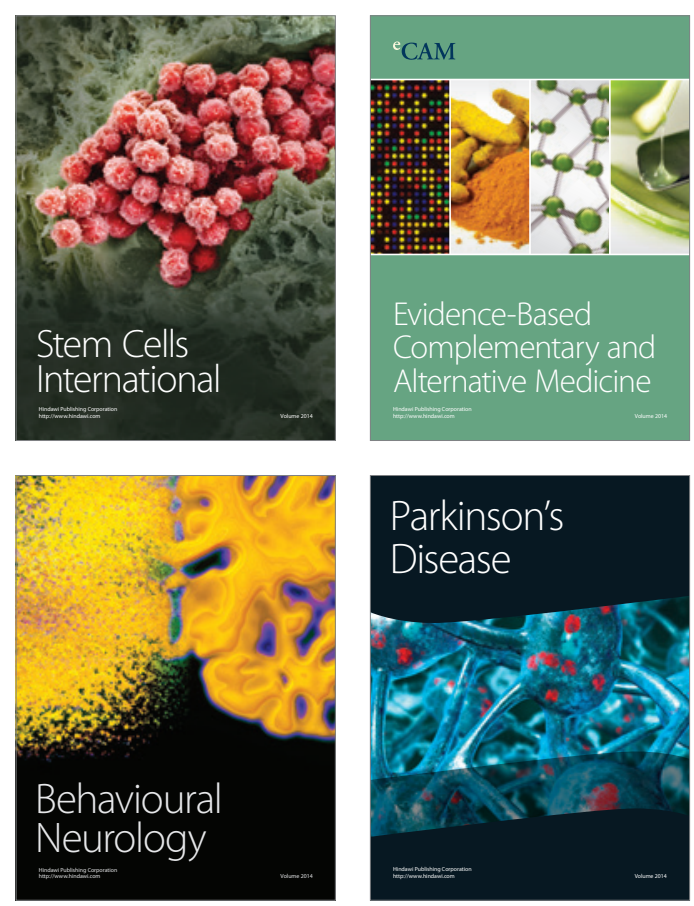

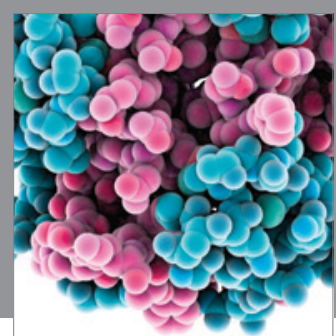

Journal of
Diabetes Research

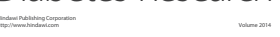

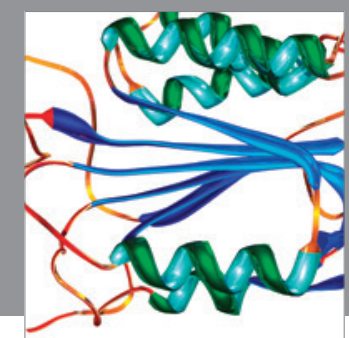

Disease Markers
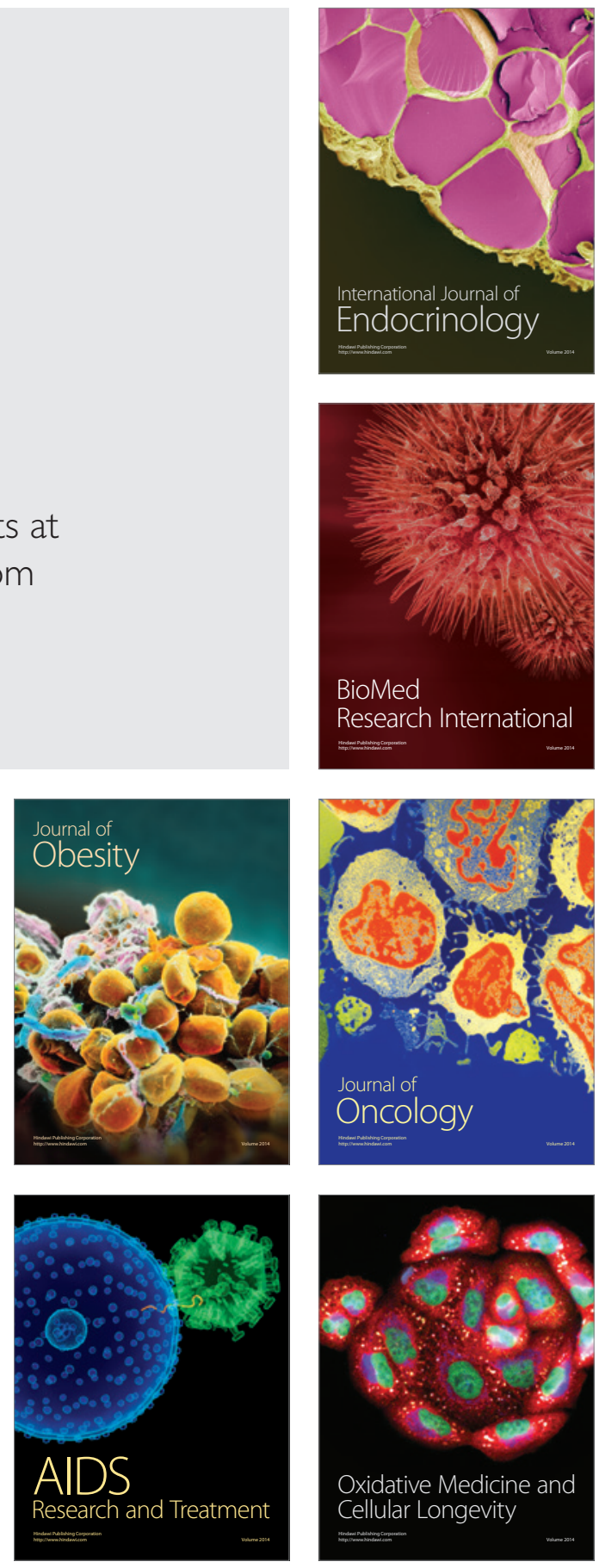